\title{
Auditory cues assist patients with Parkinson's disease (on and off L-dopa) during obstacle crossing
}

http://dx.doi.org/10.11606/1807-5509201900030333

\author{
Natalia Madalena RINALDI* \\ Marcelo Pinto PEREIRA** \\ Priscila Matias FORMAGGIO** \\ Luana Carolina MORAIS** \\ Lilian Teresa Bucken GOBBI**
}

${ }^{*}$ Center of Physical Education and Sports, Federal University of Espirito Santo, Vitória, ES, Brazil.

**Institute of Biosciences, São Paulo State University, Rio Claro, SP, Brazil.

\begin{abstract}
People with Parkinson's disease (PD) have an impaired locomotor pattern. As a result, the capacity of walking independently and the interaction with the environment can be impairment. Uneven environments can challenge even more the motor control of these patients to perform the locomotor tasks successfully. Besides of the levodopa therapy, the auditory cues have also been utilized to improve the gait parameters. However, the effects of auditory cues in gait during obstacle avoidance and the association with the levodopa effects are not known. The aim of this study was to investigate the effects of AC during obstacle crossing in people with PD (on and off L-dopa) and in healthy control participants. A total of 30 individuals participated in the study, including 15 PD patients who were tested both on and off L-dopa and 15 healthy adult controls. The task consisted of stepping over an obstacle located in the middle of the path under two conditions, i.e., cued and non-cued. We used kinematic, kinetic and electromyographic analyses to evaluate individuals' locomotor patterns. Groups differed significantly from each other for all analyses and PD patients differed significantly from all other groups when off L-dopa. ACs improved the motor control mechanisms used for obstacle crossing in people with PD. These results support the notion that external $A C$ therapy may be used as a complement to drug therapy to help improve locomotion in PD patients, even on complex tasks such as obstacle crossing.
\end{abstract}

KEYwords: Parkinson's Disease; Auditory Cues; Gait; Adaptive Locomotion.

\section{Introduction}

The positive effects of auditory cues (AC) and medication on gait have been independently tested in patients with Parkinson's disease (PD) by several investigators ${ }^{1-4}$. Studies with AC observed improvements on some free gait parameters, such as cadence and stride length ${ }^{5}$, as well as on more complex tasks, such as turning around and double tasks requiring high levels of attention ${ }^{6-8}$. However, the combined effect of AC and drug therapy on complex tasks such as obstacle crossing has not been investigated in patients with PD. PD has been shown to affect locomotor behavior during the obstacle crossing task, both during the approach and crossing phases, in patients tested on medication ${ }^{9,10}$. In a study investigating whether PD affects locomotor behavior as well as dynamic stability during obstacle crossing, Stegemoller and colleagues ${ }^{11}$ observed increased single (trailing) limb support time and a decrease in anteroposterior range of motion, also in patients on medication. These findings indicate that patients with PD strategically alter locomotor behavior in order to decrease mechanical demands and increase dynamic stability during obstacle crossing tasks.

It is well known that levodopa (L-dopa) improves stride length, velocity and muscular strength for free gait ${ }^{12-14}$. In addition, studying patients with PD before and after L-dopa, PieruCCINI-Faria, et al. ${ }^{15}$ showed that dopaminergic system may 
be involved in anticipatory temporal but not spatial step adjustments when approaching an obstacle. Also, spatial regulation during obstacle crossing was not significantly modulated by dopaminergic replacement therapy, although the trail limb vertical foot clearance was shorter during off medication when compared with healthy control $^{15}$. We have shown that auditory cues have a positive effect in walking pattern of patients with $\mathrm{PD}^{4}$, but the effects of auditory cues in PD during obstacle crossing is not known. Furthermore, the effects of associating L-dopa treatment with AC have not been investigated for obstacle crossing to date, and some questions emerge: would $\mathrm{AC}$ also help patients with $\mathrm{PD}$ cross obstacles more safely? Furthermore, would patients with PD using AC adopt the same locomotor patterns observed in healthy age-matched controls? Finally, how would

\section{Method}

This study was conducted according to the Declaration of Helsinki. This study was approved by the UNESP-RC ethics committee (Protocol \# 2635) and all participants signed an informed consent form.

30 individuals, 15 patients with PD (69.27 \pm 5.75 years old, 8 men and 7 women) tested on and off medication and 15 healthy older control participants $(70.3 \pm 6.03$ years old, 8 men and 7 women) participated in this study. These individuals also participated in the study of RiNALDI, et al. ${ }^{4}$. Patients were diagnosed by a neurologist as having stage 1-3 PD on the Hoehn \& Yahr (HY) Scale ${ }^{16}$ and were undergoing regular treatment with levodopa. Control participants did not present any neurological diseases and were matched to patients on age, gender, and height and body weight. Both patients and controls presented independent gait without using a cane or walker, preserved cognitive functions (necessary for task comprehension), no symptoms of depression, no auditory or vestibular impairments, and no osteomuscular diseases that could interfere with task performance. The inclusion criteria for patients with PD were: 1) HY stage I to III; 2) regular treatment with levodopa. In addition, the exclusion criteria for both groups (PD and healthy older control) were: 1 ) the presence of dementia (score $<24$ on Mini Mental State Examination), 2) the presence of other neurological the combination of L-dopa and AC affect patient gait on uneven surfaces? We expected that patients with PD have a worse performance than healthy older adults during obstacle crossing. We expected that this effect would be evidenced for patients with PD in off state medication. However, we expected that $\mathrm{AC}$ could bring positive changes in locomotor pattern of patients with PD during obstacle crossing in on and off state medication. Moreover, we expected that patients with PD in off state in AC condition could have a similar pattern of $\mathrm{PD}$ in on state even in irregular terrain, such as, obstacle avoidance.

Thus, the aim of this study was to assess the effects of combining AC and L-dopa on gait in patients with $\mathrm{PD}$ and compare their performance with that of healthy age-matched controls during obstacle crossing with and without AC.

or musculoskeletal disorders.

We initially conducted stride frequency tests to obtain baseline values for each participant. These variables were used to determine the frequency of the auditory cues, which were personalized and set $10 \%$ higher than each participant's preferred frequency, as described by WILLEMS, et al. ${ }^{17}$. In trials with auditory cues, participants were instructed to synchronize when their foot came in contact with the ground to the beat of the metronome.

Patients with PD data were collected in the morning at two-time points, 1) while patients were off medication for 12 hours (PD off) - and 2) one hour after taking L-dopa (PD on). Kinematic data were recorded for the right side of the body for each participant. Two infrared markers from the OPTOTRAK Cetrus motion capture system (Northern Digital Inc., Canada) were positioned on the fifth metatarsal and lateral facet of the calcaneus of each participant's right lower limb and another two were positioned on the first metatarsal and on the medial facet of the calcaneus on the left.

For electromyographic analysis, bipolar passive surface electrodes were positioned on the following muscles: tibialis anterior (TA), gastrocnemius medialis (GM) and lateralis (GL), vastus lateralis $(\mathrm{VL})$ and medialis $(\mathrm{VM})$ and biceps femoris $(\mathrm{BF})$ in the right lower limb. Electrodes were placed on each muscle surface in the direction of the muscle 
fibers, according to recommendations made by the SENIAM (surface EMG for a non-invasive assessment of muscle) project $^{18}$. In addition, a reference electrode was placed on the ulnar styloid process. Electromyographic signals were amplified through a biological signal conditioner (EMG System do Brasil $L t d a$.), with a gain of 1000 , and collected with a sampling frequency of $2000 \mathrm{~Hz}$ (20 times in the pre-amplifier and 100 times in the hardware). Data were transformed using an A/D board with an input range of +7 to -7 volts and a resolution of 12 bits.

Participants were asked to walk and cross the obstacle that was transversally positioned between two force plates in the middle of their path. Obstacle height was set to half of knee height and participants were asked to cross it with the right lower limb (leading limb). Each experimental condition (cued: with $\mathrm{AC}$ and non-cued: without $\mathrm{AC}$ ) consisted of three trials. Therefore, healthy controls performed a total of six trials and PD patients performed 12 trials ( 6 on and 6 off L-dopa). Trial presentation was randomized.

A motion capture system (OPTOTRAK Certus) was positioned sagittally to allow all markers to be visualized and to obtain three-dimensional records of marker displacement with a collection frequency of $100 \mathrm{~Hz}$. Two $50 \mathrm{~cm} \times 50 \mathrm{~cm}$ force plates (AccuGait, Advanced Mechanical Technologies, Boston, MA, USA) were embedded approximately in the middle of the pathway and covered with a black rubber carpet in order to record ground reaction force during task execution at a frequency of $200 \mathrm{~Hz}$. We used the AMTI NetForce software to collect digital data from the plates. EMG signals were recorded using the EMG System do Brasil software (Brazil), which was used to convert analog data into digital data. All data collection systems (force platforms, OPTOTRAK and EMG) were electronically synchronized. For the auditory cue, we used the Metronome Plus software to create metronome beats.

Kinematic data were filtered through a secondorder Butterworth filter with a cutoff frequency of $6 \mathrm{~Hz}$. In order to determine the cycle to be analyzed, we used the horizontal velocity of the calcaneus (calcaneus touching the ground) and the vertical velocity of the first/fifth metatarsal (foot being lifted from the ground).

Kinetic variables were filtered off-line through a fourth-order Butterworth filter with a cutoff frequency of $4 \mathrm{~Hz}$. At the beginning of each period of data collection, individuals were weighed on both force platforms in an upright position with their arms hanging along the sides of the body. Theses body mass $(\mathrm{BM})$ values were used to normalize all kinetic variables.

Electromyographic data were treated offline in two different ways: i) for RMS score collection, data were high-pass filtered at $20 \mathrm{~Hz}$ and low-pass filtered at $500 \mathrm{~Hz}$, and were later rectified; ii) for linear envelope acquisition (iEMG), after being rectified, data were filtered through a fourth-order Butterworth filter at a cutoff frequency of $10 \mathrm{~Hz}$.

All frequencies used for data processing were chosen based on the best results obtained with the residue analysis. The following kinematic variables were analyzed for one complete stride performed before reaching the obstacle: length, duration, velocity, width, duration of double support, leading and trailing foot placement in front of the obstacle, and leading and trailing toe clearance. For foot placement after crossing the obstacle, we measured leading and trailing foot placement. The kinetic data were normalized by body weight and used to calculate the braking and propulsive impulses in two directions: vertical and anterior-posterior. These variables were calculated for the leading limb (force plate 1) and for the trailing limb (force plate 2). The electromyographic variables were calculated only for the right lower limb (lead foot) in three phases: before crossing, during crossing and after crossing the obstacle, for the following muscles: tibialis anterior (TA), gastrocnemius medialis $(\mathrm{GM})$ and lateralis (GL), vastus lateralis (VL) and medialis (VM), and biceps femoris (BF). These phases were determined following SCHMITZ, et al. ${ }^{19}$, and for each phase, a linear envelope was computed to assess the level of muscular activation of each analyzed muscle.

For each analysis (kinematic, kinetic and EMG), we used a Mann-Whitney and a Wilcoxon posthoc test to assess differences among groups (control, PD off, PD on) and conditions (cued and noncued). Next, to test for possible L-dopa and/or AC effects on patient gait, we conducted a Friedman's repeated measures analysis of variance. Whenever needed, we also conducted Bonferroni posthoc analyses. Significance was set at 0.05 . Moreover, we calculated the effect size by the $\mathrm{z}$ value as suggested by COHEN $^{20}$. The effect size was calculated by the equation $(\eta 2=\mathrm{Z} / \mathrm{N})$. A large effect is $0.6 \leq \eta 2<$ 0.8 , a medium effect is $0.3 \leq \eta 2<0.5$ and a small effect is $0.0 \leq \eta 2<0.2$. These values are presented in TABLES 1,2 and 3. 


\section{Results}

\section{Kinematic analysis}

\section{Patients with PD (off L-dopa) versus Controls}

Mann Whitney test revealed significant differences between the control and PD off groups in the non-cued condition: patients with $P D$ presented relatively shorter stride length $(U=31$, $\mathrm{p}=0.02)$ and velocity $(\mathrm{U}=39, \mathrm{p}=0.007)$ and $\mathrm{a}$ trailing foot placement after crossing the obstacle $(\mathrm{U}=38, \mathrm{p}=0.006)$, as well as greater stride width $(\mathrm{U}=45, \mathrm{p}=0.015)$ and cadence $(\mathrm{U}=45.5, \mathrm{p}=0.005)$, and greater duration of double support $(\mathrm{U}=37.5$, $\mathrm{p}=0.05)$. For the cued condition, patients with PD off presented relatively slower stride velocity $(\mathrm{U}=54, \mathrm{p}=0.001)$, longer duration of double support $(\mathrm{U}=62.5, \mathrm{p}=0.03)$ and a greater trailing foot placement after crossing the obstacle $(\mathrm{U}=63$, $\mathrm{p}=0.04$ ). When conditions (cued vs. non-cued) were compared within each group, the Wilcoxon test revealed a significant difference for trailing toe clearance for the patients with PD off group ( $\mathrm{Z}=-$ 1.97, $\mathrm{p}=0.04)$ : in the cued condition, patients with PD off presented greater toe clearance. This result indicates a strategic alteration in the locomotor pattern of patients with PD off with the auditory cue, even in more challenging tasks, such as crossing obstacles. Therefore, for patients with PD off, the cued condition improved some of the measured parameters, but they still performed worse than controls overall.

\section{Patients with PD (on L-dopa) versus Controls}

The Mann Whitney test revealed significant differences between the control and PD on groups in the non-cued condition: patients with PD on presented greater stride width $(\mathrm{U}=44.5, \mathrm{p}=0.008)$ and duration of double support $(\mathrm{U}=48.5, \mathrm{p}=0.013)$. On the other hand, for the cued condition, patients had a relatively greater stride cadence, according to the Mann Whitney $(\mathrm{U}=59, \mathrm{p}=0.004)$ and Wilcoxon $(\mathrm{Z}=-3.29, \mathrm{p}=0.001)$ tests, and greater stride duration and leading toe clearance (Wilcoxon: $Z=-2.55$, $\mathrm{p}=0.011$ and $\mathrm{Z}=-2.87, \mathrm{p}=0.004$, respectively).

Friedman's and Wilcoxon posthoc tests revealed an increase in stride length and velocity after medication in the non-cued condition and an increase in cadence and duration of double support after medication in the cued condition. Interestingly, patients with PD off in the cued condition presented shorter duration of double support than patients with PD on in the non-cued condition. Thus, auditory cues had a stronger effect than medication on the duration of double support. TABLE 1 presents the kinematic data for patients with PD offlon and controls in the cued and noncued conditions.

TABLE 1 - Mean, standard deviation and effect size $\left(\eta^{2}\right)$ of kinematic variables in noncued and cued conditions for control and patients with PD in off (PDOFF) and on (PDON) medication.

\begin{tabular}{cccccccc}
\hline & \multicolumn{2}{c}{ Healthy (Control) } & \multicolumn{2}{c}{ PDOFF } & \multicolumn{2}{c}{ PDON } & $\eta^{2}$ \\
\hline Kinematic Variables & noncued & cued & noncued & cued & noncued & cued \\
\hline Stride Length(cm) & $114.1(16.1)$ & $119.1(11.5)$ & $90.3(28.9)$ & $99.4(26.9)$ & $102.1(25.6)$ & $108.8(27.5)$ & 0.32 \\
Stride Width (cm) & $18.6(6.7)$ & $15.9(4.6)$ & $22.9(8.7)$ & $21.6(8.5)$ & $23.7(9.2)$ & $23.5(9.4)$ & 0.11 \\
Cadence (steps/s) & $113.9(14.3)$ & $119.9(15.8)$ & $111.1(13.6)$ & $116.7(21.2)$ & $107.7(11.7)$ & $113.5(10.9)$ & 0.25 \\
$\quad \begin{array}{c}\text { Velocity (cm/s) } \\
\text { Stride Duration (s) }\end{array}$ & $112.8(19.2)$ & $113.2(18.2)$ & $85.7(26.2)$ & $91.2(26.8)$ & $95.9(24.3)$ & $96.6(25.3)$ & 0.20 \\
$\begin{array}{c}\text { Double Support Time } \\
\text { (s) }\end{array}$ & $0.17(0.02)$ & $0.15(0.03)$ & $0.25(0.02)$ & $0.22(0.03)$ & $0.16(0.07)$ & $0.19(0.01)$ & 0.25 \\
$\begin{array}{c}\text { Leading foot place- } \\
\text { ment after crossing the } \\
\text { obstacle (cm) }\end{array}$ & $77(15)$ & $70(16.5)$ & $60.7(12.6)$ & $59.09(11.9)$ & $65.6(15)$ & $64.7(13)$ & 0.34 \\
$\begin{array}{c}\text { Leading toe clearance } \\
\text { (cm) }\end{array}$ & $11.6(0.6)$ & $12.08(0.8)$ & $12.10(1)$ & $12.34(1.07)$ & $12.04(1.07)$ & $11.97(1.16)$ & 0.10 \\
$\begin{array}{c}\text { Trailing toe clearance } \\
\text { (cm) }\end{array}$ & $13.46(0.6)$ & $13.81(0.6)$ & $13.62(0.6)$ & $13.6(0.7)$ & $13.59(1.29)$ & $13.49(0.9)$ & 0.14 \\
\hline
\end{tabular}




\section{Force Plate 1- before obstacle crossing (leading limb)}

\section{Patients with PD (off L-dopa) versus Controls}

The Mann Whitney test indicated that patients had a relatively lower braking impulse (anteriorposterior direction) $(\mathrm{U}=28, \mathrm{p}=0.001)$ than controls in the non-cued condition. The Wilcoxon test revealed an increase in braking impulse (anterior-posterior direction) $(\mathrm{Z}=-2.76, \mathrm{p}=0.006)$, propulsive impulse (anterior-posterior direction) $(\mathrm{Z}=-2.97, \mathrm{p}=0.003)$, braking impulse (vertical direction) $(Z=-2.98$, $\mathrm{p}=0.01$ ), and propulsive impulse (vertical direction) $(\mathrm{Z}=-2.06, \mathrm{p}=0.03)$ for patients with $\mathrm{PD}$ off only in the cued condition (TABLE 2).

\section{Patients with PD (on $L$-dopa) versus Controls}

The Mann Whitney test did not indicate differences between PD patients (on L-dopa) and controls. The Wilcoxon test revealed that patients with $\mathrm{PD}$ on had an increase in braking impulse (anterior-posterior direction: $\mathrm{Z}=-2.98, \mathrm{p}=0.003$; vertical: $Z=-2.74, p=0.006$ ) and propulsive impulse (anterior-posterior direction) $(\mathrm{Z}=-2.35$, $\mathrm{p}=0.019)$ in the cued condition only (TABLE 2 ).
Friedman's and Wilcoxon post hoc tests revealed an increase in braking impulse (anterior-posterior direction) after medication in the non-cued condition $\left(\mathrm{X}^{2}(2)=16.30, \mathrm{p}=0.001\right)$, confirming previous findings that L-dopa alone improves certain locomotor parameters. Moreover, patients with PD off presented a lower braking impulse in the cued condition than did some patients with PD $o n$ in the non-cued condition, suggesting that for this variable, the auditory cue does not provide an advantage over medication (TABLE 2).

\section{Force Plate 2 - after obstacle crossing (trailing limb)}

The Mann Whitney test revealed that patients with PD off presented significantly higher propulsive impulse (vertical direction) than controls in the cued condition $(\mathrm{U}=28, \mathrm{p}=0.02)$, while the Wilcoxon test showed that patients with PD on presented a significantly higher braking impulse (anterior-posterior) in the cued condition relative to their own performance in the non-cued condition $(\mathrm{Z}=-1.88, \mathrm{p}=0.04)(\mathrm{TABLE} 2)$.

TABLE 2 - Mean, standard deviation and effect size $\left(\nabla^{2}\right)$ of kinetic variables in noncued and cued conditions for control and Parkinson's disease patients in off (PDOFF) and on (PDON) medication.

\begin{tabular}{|c|c|c|c|c|c|c|c|}
\hline \multirow{2}{*}{$\begin{array}{c}\text { Kinetic Variables } \\
\text { Leading Limb }\end{array}$} & \multicolumn{2}{|c|}{ Healthy } & \multicolumn{2}{|c|}{ PDOFF } & \multicolumn{2}{|c|}{ PDON } & \multirow[t]{2}{*}{$\eta^{2}$} \\
\hline & noncued & cued & noncued & cued & noncued & cued & \\
\hline $\begin{array}{c}\text { Braking anterior- } \\
\text {-posterior impulse } \\
\text { (Bw.s) }\end{array}$ & $-4.97(0.91)$ & $-3.91(0.98)$ & $-3.48(1.14)$ & $-3.41(1.26)$ & $-4.73(1.4)$ & $-3.76(1.2)$ & 0.15 \\
\hline $\begin{array}{l}\text { Propulsive anterior- } \\
\text {-posterior impulse } \\
\text { (Bw.s) }\end{array}$ & $3.56(0.62)$ & $4.42(0.82)$ & $3.81(0.96)$ & $4.12(1.04)$ & $4.01(0.55)$ & $4.54(0.71)$ & 0.20 \\
\hline $\begin{array}{l}\text { Braking anterior- } \\
\text {-posterior impulse } \\
\text { (Bw.s) }\end{array}$ & 40.31(7.57) & $46.29(8.26)$ & $41.75(13.78)$ & $44.38(15.04)$ & $44.2(5.84)$ & $49.42(6.65)$ & 0.50 \\
\hline $\begin{array}{l}\text { Braking vertical } \\
\text { impulse (Bw.s) }\end{array}$ & $28.79(6.36)$ & $34.03(7.61)$ & $34.5(14.78)$ & $37.08(12.59)$ & $32.53(9.03)$ & $36.12(9.07)$ & 0.20 \\
\hline Trailing Limb & noncued & cued & noncued & cued & noncued & cued & \\
\hline $\begin{array}{c}\text { Braking anterior- } \\
\text {-posterior impulse } \\
\text { (Bw.s) }\end{array}$ & $-4.62(4.08)$ & $-3.35(2.42)$ & $-3.10(0.85)$ & $-3.61(2.49)$ & $-4.57(3.86)$ & $-2.99(0.7)$ & 0.10 \\
\hline $\begin{array}{l}\text { Propulsive anterior- } \\
\text {-posterior impulse } \\
\text { (Bw.s) }\end{array}$ & $3.05(2.06)$ & $4.04(1.79)$ & $4.01(1.64)$ & $4.24(1.58)$ & $4.41(0.9)$ & $4.59(1.47)$ & 0.14 \\
\hline $\begin{array}{c}\text { Braking anterior- } \\
\text {-posterior impulse } \\
\text { (Bw.s) }\end{array}$ & $32.14(5.08)$ & $39.65(10.63)$ & $34.08(13.36)$ & $39.52(12.53)$ & $39.01(7.13)$ & $34.92(7.86)$ & 0.10 \\
\hline $\begin{array}{l}\text { Braking vertical } \\
\text { impulse (Bw.s) }\end{array}$ & $34.96(14.38)$ & 45.74(19.19) & $48.66(18.36)$ & $51.95(18.71)$ & $47.33(13.98)$ & $47.51(15.23)$ & 0.13 \\
\hline
\end{tabular}




\section{Electromyographic Analysis}

The Wilcoxon test revealed differences between conditions (cued vs. non-cued) for both groups in terms of certain muscle groups.

\section{PD off versus Controls}

Overall, patients with PD off presented lower muscle activity than controls for the following muscles in the non-cued condition: VL (before obstacle crossing) $(\mathrm{Z}=-1.91, \mathrm{p}=0.05), \mathrm{VM}$ (before obstacle crossing) $(Z=-2.10, p=0.03)$, TA (during obstacle crossing) $(\mathrm{Z}=-1.99, \mathrm{p}=0.04)$, TA (after obstacle crossing) $(Z=-1.91, p=0.05)$, and VM (after obstacle crossing) $(\mathrm{Z}=-2.16, \mathrm{p}=0.03)$. In the cued condition, patients with PD off displayed an increase in the activation of VL muscles (before obstacle crossing), VM muscles (before obstacle crossing), TA muscles (after obstacle crossing) and a decrease in activation of TA muscles (during obstacle crossing) and VM muscles (after obstacle crossing) relative to their own performance in the non-cued condition (TABLE 3).

\section{PD on versus Controls}

The patients with $\mathrm{PD}$ on presented significantly lower activation of $B F$ muscles $(U=50, p=0.016)$ and VM muscles $(U=54, p=0.026)$ than controls after obstacle crossing only in the non-cued condition. Also, Wilcoxon tests indicated greater activity for BF muscles in patients with PD on in the cued versus the non-cued condition $(\mathrm{Z}=-2.98$, $\mathrm{p}=0.003)$ (TABLE 3).

The Friedman's test revealed that in the noncued condition, patients with PD on presented significantly lower activation of the $\mathrm{BF}\left(\mathrm{X}^{2}(2)=10.19\right.$, $\mathrm{p}=0.0017)$ and $\mathrm{GM}$ muscles $\left(\mathrm{X}^{2}(2)=16.95\right.$, $\mathrm{p}=0.001)$ during obstacle crossing. In the non-cued condition, patients with PD had lower BF and GM activity after medication intake (TABLE 3).

TABLE 3 - Mean, standard deviation and effect size $(\bigotimes 2)$ of emg variables in noncued and cued conditions for control and Parkinson's disease patients in off (PDOFF) and on (PDON) medication.

\begin{tabular}{cccccccc}
\hline \multicolumn{2}{c}{ Healthy } & \multicolumn{2}{c}{ PDOFF } & \multicolumn{2}{c}{ PDON } & $\eta^{2}$ \\
\hline Muscles & noncued & cued & noncued & cued & noncued & cued & \\
\hline Before & & & & & & & \\
& & & & & & & \\
VL & 304.69 & 602.15 & 457.91 & 708.14 & 516.29 & 632.27 & 0.11 \\
& $(150.58)$ & $(390.32)$ & $(164.72)$ & $(224.77)$ & $(187.53)$ & $(252.91)$ & \\
BF & 475.44 & 564.45 & 644.36 & 709.21 & 814.61 & 638.55 & 0.10 \\
& $(114.85)$ & $(203.95)$ & $(236.82)$ & $(297.83)$ & $(187.65)$ & $(286.03)$ & \\
GL & 1888.76 & 1205.59 & 1305 & 1286 & 1312 & 1102 & 0.22 \\
& $(667.57)$ & $(460.17)$ & $(252.20)$ & $(266.66)$ & $(504.60)$ & $(272.07)$ & \\
TA & 640.40 & 825.79 & 825.16 & 822.71 & 881.19 & 987.26 & 0.10 \\
& $(305.60)$ & $(594.03)$ & $(315.23)$ & $(291.71)$ & $(329.98)$ & $(245.31)$ & \\
GM & 637.37 & 803.90 & 680.29 & 818.09 & 817.63 & 747.10 & 0.10 \\
& $(338.96)$ & $(169.73)$ & $(252.85)$ & $(218.35)$ & $(196.44)$ & $(254.47)$ & \\
VM & 422.65 & 420.37 & 434.87 & 540.04 & 464.80 & 507.27 & 0.19
\end{tabular}

\begin{tabular}{rccccccc}
\hline During & & & & & \\
VL & $28.32(11.12)$ & $29.12(11.89)$ & $28.05(13.78)$ & $30.28(11.27)$ & $25.23(9.85)$ & $16.89(8.05)$ & 0.10 \\
BF & $22.58(13.72)$ & $23.11(7.27)$ & $29.54(13.84)$ & $21.17(9.50)$ & $18.10(8.26)$ & $18.93(9.46)$ & 0.11 \\
GL & $73.21(34.31)$ & $82.71(42.11)$ & $61.21(22.84)$ & $57.09(22.16)$ & $70.89(34.18)$ & $64.53(24.25)$ & 0.12 \\
TA & $56.30(20.90)$ & $55(28.11)$ & $59.54(15.49)$ & $42.61(22.67)$ & $42.08(12.38)$ & $42.38(14.62)$ & 0.10 \\
& 102.36 & & & & & & \\
GM & $(55.91)$ & $89.55(45.93)$ & $99.27(33.87)$ & $84.33(43.05)$ & $54.29(12.24)$ & $45.78(18.38)$ & 0.10 \\
VM & $23.19(10.93)$ & $21.76(11.86)$ & $20.92(10.82)$ & $30.62(19.86)$ & $27.63(11.15)$ & $28.91(13.66)$ & 0.12 \\
\hline After & & & & & & \\
& & & & & & & \\
VL & $(164.13)$ & $(198.61)$ & $(189.60)$ & $(172.32)$ & $(102.33)$ & $(106.88)$ & 0.13 \\
\hline
\end{tabular}


TABLE 3 - (continued)

\begin{tabular}{|c|c|c|c|c|c|c|c|}
\hline \multirow[b]{2}{*}{ Muscles } & \multicolumn{2}{|c|}{ Healthy } & \multicolumn{2}{|c|}{ PDOFF } & \multicolumn{2}{|c|}{ PDON } & \multirow[t]{2}{*}{$\eta^{2}$} \\
\hline & noncued & cued & noncued & cued & noncued & cued & \\
\hline \multicolumn{8}{|l|}{ After } \\
\hline $\mathrm{BF}$ & $\begin{array}{c}350.05 \\
(120.08)\end{array}$ & $\begin{array}{c}276.87 \\
(124.45)\end{array}$ & $\begin{array}{l}244.78 \\
(99.27)\end{array}$ & $\begin{array}{c}291.92 \\
(115.14)\end{array}$ & $\begin{array}{l}217.06 \\
(94.33)\end{array}$ & $\begin{array}{l}277.56 \\
(97.02)\end{array}$ & 0.11 \\
\hline GL & $\begin{array}{c}771.83 \\
(294.61)\end{array}$ & $\begin{array}{c}691.27 \\
(172.47)\end{array}$ & $\begin{array}{c}631.19 \\
(290.65)\end{array}$ & $\begin{array}{c}715.69 \\
(269.87)\end{array}$ & $\begin{array}{c}567.98 \\
(214.43)\end{array}$ & $\begin{array}{c}732.10 \\
(291.67)\end{array}$ & 0.17 \\
\hline TA & $\begin{array}{c}299.11 \\
(100.65)\end{array}$ & $\begin{array}{c}478.66 \\
(174.22)\end{array}$ & $\begin{array}{c}500.82 \\
(221.66)\end{array}$ & $\begin{array}{c}340.55 \\
(106.39)\end{array}$ & $\begin{array}{c}439.05 \\
(152.60)\end{array}$ & $\begin{array}{c}315.30 \\
(103.46)\end{array}$ & 0.18 \\
\hline GM & $\begin{array}{c}669.39 \\
(268.90)\end{array}$ & $\begin{array}{c}550.46 \\
(147.94)\end{array}$ & $\begin{array}{c}598.78 \\
(169.22)\end{array}$ & $\begin{array}{c}477.74 \\
(114.33)\end{array}$ & $\begin{array}{c}430.55 \\
(123.91)\end{array}$ & $\begin{array}{c}231.17 \\
(103.49)\end{array}$ & 0.10 \\
\hline VM & $\begin{array}{c}417.48 \\
(206.79)\end{array}$ & $\begin{array}{c}365.54 \\
(176.14)\end{array}$ & $\begin{array}{l}298.53 \\
(131.5)\end{array}$ & $\begin{array}{c}197.27 \\
(107.26)\end{array}$ & $\begin{array}{l}218.76 \\
(99.08)\end{array}$ & $\begin{array}{l}250.08 \\
(96.51)\end{array}$ & 0.11 \\
\hline
\end{tabular}

\section{Discussion}

In the present study, we investigated the effects of auditory cues on gait in patients with PD (on and off L-Dopa) and age-matched control participants during obstacle crossing. Overall, we found that L-Dopa off patients performed worse than controls and patients with $\mathrm{PD}$ on for most variables tested. The cue condition improved the pattern of locomotion during obstacle crossing for patients with PD (both off and on L-Dopa). For some variables, the auditory cue had a stronger effect than medication in improving locomotion.

We observed that AC caused patients with PD and healthy controls to alter their locomotor patterns during obstacle crossing. Rhythmic stimulation helped both groups cross obstacles safely by increasing the safety margin and muscular activation. In the cued condition, the performance of patients with PD on was not significantly different than that of healthy controls, suggesting that the combined therapeutic approach can confer benefits beyond those observed with either treatment alone. As expected and shown by previous authors, patients with PD on presented an improved locomotor pattern compared to when they were in off state. However, with AC, patients with PD off had better locomotor control than some patients with PD on without AC. Therefore, we conclude that AC may be better than L-dopa for gait parameters in some patients with $\mathrm{PD}$, but further studies are needed to support these findings. Also, AC improved the safety margin for the leading limb and propulsive braking impulses. This is an important result, because with rhythmic auditory cues, patients were able to raise their leg by increasing propulsion. Patients with PD on presented similar kinematic, kinetic and electromyographic scores as controls during the approach and crossing phases. These results suggest that ACs improve sensorial processing used to perform increasingly challenging motor actions. Based on these results, additional sensorial and attentional resources must be targeted in rehabilitation programs to increase the effect of $\mathrm{AC}$ on the locomotor pattern of patients with $\mathrm{PD}$, mainly during complex tasks, such as crossing obstacles.

The healthy central nervous system uses visual information to track an obstacle in the environment and process its characteristics (e.g., height and width) in order to make motor adjustments in the lower limb to safely and successfully avoid the obstacle ${ }^{21}$. Patients with PD off medication are usually slower at processing this information ${ }^{22}$ and may also have an impaired visual system ${ }^{23}$, which is why they need more time to explore obstacles and remain in double support for a longer period of time. However, with medication and AC, patients with PD did not need more time to process obstacle features, as verified by a decrease in stride duration and double support. These results indicate that a combination of sensorial information and drugs is effective in improving gait stability when patients must accomplish more complex tasks. L-dopa increases dopamine levels in the basal ganglia ${ }^{24}$, which improves motor symptoms, while ACs reach the supplementary motor area through the cortex, providing cues to guide the movement ${ }^{1}$. Auditory cues increased the safety margin for the leading limb, which, as previously explained, helps patients increase their propulsive 
impulse while reducing the risk of tripping or falling. After avoiding the obstacle, the ACs helps patients increase their braking impulse following a disturbing situation. We also observed an increase in BF muscle activation after obstacle crossing, which indicates better stability and foot positioning on the floor and a better ability to maintain synchronization with the AC.

During the approach phase to the obstacle in the non-cued condition, patients with PD (off and on L-dopa) presented decreased stride length, cadence and velocity and increased stride width and double support relative to controls, which indicates postural instability, hypometry and hypokinesia, and is in line with findings by Vitorio, et al ${ }^{9}$. We also observed weaker force for patients relative to controls before obstacle crossing, which reflects the reduced motor planning and force (accompanied by muscular rigidity) commonly observed in PD. After crossing the obstacle, patients with PD also positioned their support limb closer to the obstacle, which reflects the expected reduced force and stability. These results corroborate with those of VAN HEDEL, WALDVOLGeL and DIETZ ${ }^{25}$, which verified that patients with PD performed worse on obstacle crossing than healthy controls. However, during the cued condition, those differences decreased and patients with PD (off and on L-dopa) presented similar performance to healthy controls on stride width, length and force generation peaks. Again, AC may help patients with PD strategically adjust locomotor patterns, even in more complex situations.

When patients were on L-dopa (PD on), they still differed significantly from controls, and some of these differences were reduced during the cued condition. Galna, Murphy and Morris ${ }^{10}$ investigated the locomotor pattern of patients with PD on and healthy controls during obstacle crossing and found that patients approached the obstacle more slowly and presented higher double support, indicating higher postural instability. While patients scored similarly to controls on safety margin and foot placement in front of the obstacle (as seen in our own study), they scored differently on foot placement after obstacle crossing, for example, they placed their lead foot closer to the obstacle after crossing. While processing sensorial information and motor planning for obstacle crossing in the GALNA, MURPHY and MORRIS ${ }^{10}$ study appeared similar between groups, patients with PD presented decreased muscular activation of VL and BF during the swing phase (crossing) and propulsion, which likely indicates reduced recruitment of muscular fibers when performing a more challenging task. Although patients in the current study were tested during the beginning or moderate stages of patients with PD, we still observed alterations in CNSmediated commands; perhaps at more advanced stages of PD, differences in task planning (foot placement in front of the obstacle) may become more evident.

In sum, L-dopa reduced certain PD symptoms such as hypokinesia and bradykinesia, in line with other studies that investigated gait in patients with $\mathrm{PD}^{22,15}$ and consistent with the observed decreased muscular activation of BF and GM, which facilitate motor adjustments before obstacle crossing. However, the increased knee flexor activation was not enough to increase safety margins. In the more challenging uneven surface obstacle crossing task presented in our study, medication together with AC were not enough to increase safety margins, leaving patients more vulnerable to falling. In the cued condition, patients with PD on showed a decrease in double support, indicating improved postural stability before obstacle crossing. Interestingly, patients with PD off had higher double support scores in the cued condition than patients with PD on in the non-cued condition, which reveals that $\mathrm{AC}$ may be better than levodopa for postural stability, which is essential for successful movement. Also, patients did not differ significantly on muscular activation scores before and after taking medication, which suggests that ACs act as an important sensory reinforcement to modulate motor responses in these patients.

With the aid of AC, patients improved on some parameters (relative to the non-cued condition), even in the more challenging situation presented in this study (i.e., obstacle crossing on an uneven surface). Moreover, auditory cue could not act as a dual task, because people with PD have to divide the attention between crossing obstacle and synchronize the heel contact with the metronome. However, NANHOEMAHABIER, et al. ${ }^{26}$ also showed that patients with PD can benefit from auditory cue even in obstacle avoidance (complex task) and metronome could not be considered as a dual task that negatively affects gait. Although changes in locomotor patterns were observed among these patients with the aid of the rhythmic AC stimulation, this may not be enough to make their performance entirely successful. One possible solution may be to direct patients' attention to ACs at several points along the path, especially during the more challenging tasks, such as obstacle crossing. One limitation of this study was that foot 
placement on the ground was not synchronize with auditory cue. Although we found positive effects of auditory cue on gait of patients with PD, we could not confirm how these patients use this type of cue to improve their locomotor performance. Moreover, to use this type of cue in some cases could be a complex task for patients with PD and it may be considered for rehabilitation sections. For example, Platz, BROWN and MARSDEN ${ }^{27}$ did not find any effect of auditory cue on gait of patients with PD that shows that cues could interfere the kinematics aspects of the movement.

Future studies should monitor foot placement synchronization in order to determine the exact moments at which patients with PD need additional assistance. Synchronization may also help elucidate whether some changes observed at either the approach or crossing phases may reveal that patients prioritize the synchronization task at the expense of making the proper locomotor adjustments necessary for obstacle crossing. Finally, displacement analyses in the mediolateral and anteroposterior directions would show strategies adopted by patients with PD to cross obstacles, and whether these strategies negatively affect postural stability.

We conclude that AC may be better than L-dopa for some gait parameters in uneven terrain for patients with PD, but further studies are needed to support these findings. Our results suggest that L-dopa combined with AC treatment may be an effective way of improving performance in patients with PD. Finally, future studies should target additional sensorial and attentional resources to increase the effect of $\mathrm{AC}$ on the locomotor pattern of patients with $\mathrm{PD}$.

\section{Resumo}

Dica auditiva pode auxilar pacientes com doença de Parkinson (com e sem levodopa) durante a ultrapassagem de obstáculo

Pessoas com doença de Parkinson (DP) apresentam um padrão locomotor alterado. Como resultado, a capacidade de andar independente e a interação com o ambiente pode ficar comprometida. Ambientes irregulares podem desafiar ainda mais o controle motor destes pacientes para realizar a tarefa locomotora com sucesso. Além da terapia com levodopa, a dica auditiva tem sido utilizada para melhorar os parâmetros locomotores. Entretanto, o efeito da dica auditiva na marcha durante a ultrapassagem de obstáculos e a associação com a levodopa não são conhecidos. 0 objetivo deste estudo foi investigar o efeito da dica auditiva durante a ultrapassagem de obstáculos em pessoas com doença de Parkinson (com e sem levodopa) e idosos sadios. 30 individuos participaram deste estudo, 15 pacientes com DP e 15 idosos sadios. A tarefa foi ultrapassar um obstáculo localizado no meio da passarela em duas condições, com e sem dica auditiva. As análises cinemática, cinética e eletromiográfica foram utilizadas para analisar o padrão locomotor. Os grupos foram diferentes, quando os pacientes com DP estavam sem efeito da levodopa. Dica auditiva melhorou os mecanismos de controle motor durante a ultrapassagem de obstáculos em pacientes com DP. Estes resultados suportam a utilização de dicas sensoriais externas como um complemento à terapia medicamentosa para melhorar o padrão locomotor em pacientes com DP mesmo em tarefas complexas, como por exemplo, ultrapassar um obstáculo.

PalaVRAS-Chave: Doença de Parkinson; Dica Auditiva; Marcha; Locomoção Adaptativa.

\section{References}

1. Hausdorff JM, Lowenthal J, Herman T, Gruendlinger L, Peretz C, Giladi N. Rhythmic auditory stimulation modulates gait variability in Parkinson's disease. Eur J Neurosci. 2007;26:2369-2375.

2. Nieuwboer A, Chavret F, Willems AM, Desloovere K. Does freezing in Parkinson's disease change limb coordination? J Neurol. 2007;254:1268-1277. 
3. Rochester L, Baker K, Niewboer A, Burn D. Targeting dopa-sensitive and dopa-resistant gait dysfunction in Parkinson's disease: Selective responses to internal and external cues. Mov Disord. 2011;26(3):430-435.

4. Rinaldi NM, Pereira MP, Formaggio PM, Morais LC, Gobbi LTB. Positive effects of auditory cue in locomotor pattern of people with Parkinson's disease (off and on medication). Rev Bras Educ Fís Esporte. 2014;28(4):561-570.

5. Ledger S, Galvin R, Lynch D, Stokes EK. A randomized controlled trial evaluating the effect of an individual auditory cueing device on freezing and gait speed in people with Parkinson's disease. BMC Neurol. 2008;8(46):1-6.

6. Baker K, Rochester L, Nieuwboer A. The immediate effect of attentional, auditory, and a combined cue strategy on gait during single and dual tasks in Parkinson’s Disease. Arch Phys Med Rehab. 2007;88:1593-1600.

7. Nieuwboer A, Baker K, Willems AM, Jones D, Spildooren J, Lim I, et al. The short-term effects of different cueing modalities on turn speed in people with Parkinson's disease. Neurorehab Neural Re. 2009;23(8):831-836.

8. Willems AM, Nieuwboer A, Chavret F, Desloovere K, Dom R, Rochester L, et al. Turning in Parkinson's disease patients and controls: The effect of auditory cues. Mov Disord. 2007;22(13):1871-1878.

9. Vitorio R, Pieruccini-Faria F, Stella F, Gobbi S, Gobbi LT. Effects of obstacle height on obstacle crossing in mild Parkinson's disease. Gait Posture. 2010;31:143-146.

10. Galna B, Murphy AT, Morris ME. Obstacle crossing in people with Parkinson's disease: foot clearance and spatiotemporal deficits. Hum Mov Sci. 2010:29(5):843-852.

11. Stegemöller EL, Buckley TA, Pitsikoulis C, Barthelemy E, Roemmich R, Hass CJ. Postural instability and gait impairment during obstacle crossing in Parkinson's Disease. Arch Phys Med Rehab. 2012;93:703-709.

12. Blin O, Ferrandez AM, Pailhous J, Serratrice G. Dopa-sensitive and Dopa resistant gait parameters in Parkinson's disease. J Neurol Sci. 1991;103:1-54.

13. Cioni M, Richards CL, Malouin F, Bedard PJ, Lemieux R. Characteristics of the eletromyographic patterns of lower limb muscles during gait in patients with Parkinson's disease when off and on L-Dopa treatment. Ital J Neurol Sci. 1997; 18:195-208.

14. Morris ME, McGinley J, Hurcham F, Collier J, Iansek R. Constraints on the kinetic, kinematic and spatiotemporal parameters of gait in Parkinson's disease. Hum Mov Sci. 1999;18:461-483.

15. Pieruccini-Faria F, Vitório R, Almeida QJ, Silveira CR, Caetano MJ, Stella F, et al. Evaluating the acute contributions of dopaminergic replacement to gait with obstacles in Parkinson's disease. J Motor Behav. 2013;45(5):369-380.

16. Goetz CG, Poewe W, Rascol O, Sampaio C, Stebbins GT, Counsell C, et al. Movement Disorder Society Task Force Report on the Hoehn and Yahr Staging Scale: Status and Recommendations. Mov Disord. 2004;19(9):1020-28.

17. Willems AM, Nieuwboer A, Chavret F, Desloovere K, Dom R, Rochester L, et al. The use of rhythmic auditory cues to influence gait in patients with Parkinson's disease, the differential effect for freezers and non-freezers, an explorative study. Disabil Rehabil. 2006;28(11):721-728.

18. Hermens HJ, Freriks B, Disselhorst-Klug C, Rau G. Development of recommendations for SEMG sensors and sensor placement procedures. J Electromyogr Kinesiol. 2000;10:361-374.

19. Schmitz A, Silder A, Heiderscheit B, Mahoney J, Thelen DG. Differences in lower-extremity muscular activation during walking between healthy older and young adults. J Electromyogr Kinesiol. 2009;1319:103-111.

20. Cohen J. Statistical power analysis for the behavioral sciences. Hillsdale: Lawrence Earlbaum Associates; 1988.

21. Santos LC, Moraes R, Patla AE. Visual feedforward control in human locomotion during avoidance of obstacles that change size. Motor Control. 2010;14:424-439.

22. Morris ME, Huxham F, Mcgindly J, Dodd K, Iansek R. The biomechanics and motor control of gait in Parkinson disease. Clin Biomech. 2001;16:459-470.

23. Armstrong RA. Visual signs and symptoms of Parkinson's disease. Clin Exp Optom. 2008;91(2):129-138. 
24. Devos D, Defebvre L, Bordet R. Dopaminergic and non-dopaminergic pharmacological hypotheses for gait disorders in Parkinson's disease. Fundam Clin Pharmacol. 2010;24(4):407-421.

25. van Hedel HJA, Waldvogel D, Dietz V. Learning a high-precision locomotor task in patients with Parkinson's disease. Mov Disord. 2006;21(3):406-411.

26. Nanhoe-Mahabier W, Delval A, Snijders AH, Weerdesteyn V, Overeem S, Bloem BR. The possible price of auditory cueing: influence on obstacle avoidance in PD. Mov Disord. 2012;27(4):575-578.

27. Platz T, Brown RG, Marsden CD. Training improves the speed of aimed movements in Parkinson's disease. Brain. $1998 ; 121: 505-514$.

\begin{tabular}{r|l} 
ENDEREÇO DE CORRESPONDÊNCIA: & \\
Natalia Madalena Rinaldi & Submitted: 20/o5/2016 \\
Av. Fernando Ferrari, 514 & 1st. Review: 21/09/2017 \\
Vitoria - ES - BRAZIL & 2nd. Review: 30/11/2017 \\
CEP: 29075-810 & Accepted: 20/12/2017 \\
E-mail: natalia.rinaldi@ufes.br &
\end{tabular}

